\title{
Metabolism of the Polysaccharides of Human Dental Plaque: Release of Dextranase in Batch Cultures of Streptococcus mutans
}

\author{
By GWEN J. WALKER, * ALEXANDRA PULKOWNIK AND \\ JILL G. MORREY-JONES
}

Institute of Dental Research, 2 Chalmers Street, Surry Hills, Sydney, New South Wales 2010, Australia

(Received 25 February 1981; revised 28 April 1981)

\begin{abstract}
Dextranase activity was determined in cell extracts and cell-free filtrates of Streptococcus mutans strains which had been grown in batch culture. Exo-dextranase activity was located chiefly in cell extracts, whereas endodextranase was mainly extracellular. Release of endo-dextranase began early in the exponential phase of growth, and ended when the concentration of residual sugar was low. Thus, dextranase expression was associated with rapidly growing cells, and the yield of dextranase was increased several fold when the initial concentration of D-glucose in the medium was changed from $0.5 \%$ to $2 \%$. The endo-dextranase was not stable at $\mathrm{pH} 5$, and control of the $\mathrm{pH}$ of the culture was essential to preserve active dextranase during overnight growth. Strain Ingbritt (serotype $c$ ) and serotype $d$ strains were the best dextranase producers; other strains (serotypes $a, b, c, e$ and $f$ ) displayed much lower activity. The ability to produce endo-dextranase, and to synthesize $\alpha$-D-glucans with a high proportion of $(1 \rightarrow 3)$-linked sequences, appeared to be related properties. The possibility is discussed that the release of two enzymes, namely endodextranase and the D-glucosyltransferase (GTF-I) that synthesizes $(1 \rightarrow 3)$ - $\alpha$-D-glucan, are factors that contribute to the cariogenicity of $S$. mutans serotype $d$.
\end{abstract}

\section{INTRODUCTION}

A significant proportion of bacteria in human dental plaque produce enzymes capable of hydrolysing $(1 \rightarrow 6)$ - $\alpha$-D-glucosidic linkages in dextran (Staat et al., 1973). An investigation into the occurrence of intracellular dextranases in batch cultures of human oral streptococci (Dewar \& Walker, 1975) revealed that over $33 \%$ of the strains contained 1,6- $\alpha$-D-glucan glucohydrolase, an exo-dextranase (EC 3.2.1.70) previously reported in Streptococcus mitis (Walker \& Builder, 1967). The enzyme was capable of releasing D-glucose from dextrans (Walker \& Pulkownik, 1973) and from oligosaccharides derived from dextrans (Walker \& Pulkownik, 1974). Several strains, later classified as Streptococcus mutans (Hare, 1977) produced an endo-dextranase (EC 3.2.1.11), that released oligosaccharides of the isomaltose series from dextran. Some of the $S$. mutans strains produced both types of dextranase. Water-insoluble glucans produced from sucrose by Streptococcus sanguis and $S$. mutans, which contain a proportion of $(1 \rightarrow 6)$-linked sequences of D-glucose residues, were also substrates for $S$. mutans endo-dextranase (Hare et al., 1978).

Many reactions of $S$. mutans are greatly influenced by small amounts of dextran. These include the aggregation of the cells (Gibbons \& Fitzgerald, 1969), their adherence to hard surfaces (Gibbons \& Van Houte, 1973), the synthesis of extracellular glucans from sucrose (McCabe \& Smith, 1973), the distribution of D-glucosyltransferases between cells and culture filtrate, and the dextran-binding capacity of the cells (Spinell \& Gibbons, 1974). Such reactions would be sensitive to low levels of dextranase, and it is therefore important that 
dextranase production by $S$. mutans be assessed correctly. It can be inferred from discrepant reports on $S$. mutans dextranase that one or more factors may make it difficult to determine its activity accurately. The existence of the enzyme has variously been acknowledged (Guggenheim \& Burkhardt, 1974; Germaine et al., 1977), denied or simply neglected. We have investigated the release of endo-dextranase by $S$. mutans grown in batch culture under conditions commonly employed in different laboratories. The results indicate that is not feasible to expect consistent values for dextranase activity to emerge from batch growths.

\section{METHODS}

Organisms and growth conditions. Streptococcus mutans strains AHT and BHT were received from D. D. Zinner, FA-1 and K1-R from R. J. Fitzgerald, JC2 from J. Carlsson, GS-5 from A. Bleiweis, Ingbritt from B. Krasse, B 13 from S. Edwardsson, OMZ176 from B. Guggenheim, LM7 from L. A. Thomson, and OMZ65 and OMZ175 from D. Bratthall.

The organisms were grown in a medium (Van Houte \& Saxton, 1971) that contained (per I distilled water): $20 \mathrm{~g}$ Trypticase Peptone, $5 \mathrm{~g}$ yeast extract, $4 \mathrm{~g} \mathrm{~K}_{2} \mathrm{HPO}_{4}, 1 \mathrm{~g} \mathrm{KH}_{2} \mathrm{PO}_{4}, 2 \mathrm{~g} \mathrm{NaCl}$, and usually $20 \mathrm{~g} \mathrm{D}$-glucose or D-fructose. Dialysed medium consisted of that fraction of the complete medium that passed through an Amicon hollow-fibre filter cartridge. Bacteria were grown under anaerobic conditions $\left(\mathrm{N}_{2} / \mathrm{CO}_{2}, 95: 5\right)$ at $37^{\circ} \mathrm{C}$ in $350 \mathrm{ml}$ medium in a 11 capacity New Brunswick Multigen model F-1000 fermenter; the $\mathrm{pH}$ of the culture was maintained at $6.0 \pm 0.05$ by automatic addition of $\mathrm{NaOH}$.

Fractionation of cultures. Samples of the culture were cooled to $4{ }^{\circ} \mathrm{C}$ and centrifuged for $10 \mathrm{~min}$ at $12000 \mathrm{~g}$. Portions (about $20 \mathrm{ml}$ ) of the cell-free filtrate were dialysed against $50 \mathrm{mM}$-sodium citrate buffer (pH 6), with two changes of buffer over a $20 \mathrm{~h}$ dialysis period. The cells were washed twice with the same buffer, resuspended in one-seventh of the original volume of the culture sample, and disintegrated by shaking with $0.1 \mathrm{~mm}$ diam. glass beads (Glasperlen; Braun, Melsungen, F.R.G.) in a cell homogenizer (MSK; Braun) for 3 min at $2^{\circ} \mathrm{C}$. The beads were filtered off, and the filtrate was centrifuged at $34800 \mathrm{~g}$ for $10 \mathrm{~min}$ to yield a soluble extract which was dialysed against $50 \mathrm{mM}$-sodium citrate buffer $(\mathrm{pH} 6 \cdot 0)$.

Determination of dextranase activity. Endo-dextranase activity of dialysed cell-free filtrates and cell extracts was determined from the release of reducing sugars in digests $(1 \mathrm{ml})$ that contained $15 \mathrm{mg}$ dextran (Sigma, Type 2000) and an appropriate volume of enzyme, usually $0.5 \mathrm{ml}$, in $25 \mathrm{mM}$-sodium citrate buffer (pH 6.0). Samples were taken at intervals for up to $24 \mathrm{~h}$ for the determination of reducing power with neocuproine reagent (Dygert $e t$ al., 1965). One unit of activity was defined as the amount of enzyme that released $1 \mu \mathrm{mol}$ reducing power $\mathrm{min}^{-1}$ under the conditions of the assay.

Exo-dextranase activity of cell-free filtrates and cell extracts was determined by measuring the release of D-glucose from isomaltose as described previously (Dewar \& Walker, 1975). One unit of activity was defined as the amount of enzyme that released $1 \mu \mathrm{mol} \mathrm{D}$-glucose $\mathrm{min}^{-1}$.

Determination of dry weight of cells. Triplicate portions of the culture $(5 \mathrm{ml})$ were centrifuged and washed once with sodium citrate buffer as described above. The pellets were then washed with water and dried to constant weight at $90^{\circ} \mathrm{C}$. The activities of cell extracts and cell-free filtrates were converted from units $\mathrm{l}^{-1}$ to units per $\mathrm{g}$ dry wt of the cells with which they were originally associated.

Analysis of $S$. mutans $\alpha$-D-glucans. Methylation analysis and determination of the limit of hydrolysis by endo-dextranase were as described by Hare et al. (1978).

\section{RES ULT S \\ Location of endo- and exo-dextranases}

The distribution of the two dextranases between cells and cell-free filtrates of several strains of $S$. mutans was determined. The organisms were grown in complete medium supplemented with $2 \%(\mathrm{w} / \mathrm{v})$ glucose with the $\mathrm{pH}$ controlled at 6.0 , and harvested in the stationary phase of growth. The bulk of the exo-dextranase (74-79\%) was present in the cell extracts, whereas the major portion of the endo-dextranase (60-90\%) was extracellular (Table 1). No glucose was released during the incubation of the cell-free filtrates with dextran in the activity tests, so the initial stages of dextran degradation were mediated entirely by endo-dextranase. The results that follow therefore refer to the endo-dextranase activity of culture filtrates. 


\section{Table 1. Distribution of endo-dextranase and exo-dextranase activities in batch cultures} of Streptococcus mutans

Activities are expressed as units ( $\mathrm{g}$ dry wt cells) $)^{-1}$. One unit of endo-dextranase releases $1 \mu \mathrm{mol}$ reducing power from dextran $\min ^{-1}$, and one unit of exo-dextranase releases $1 \mu \mathrm{mol}$ D-glucose from isomaltose $\mathrm{min}^{-1}$.

$\begin{array}{lccccc}\text { Strain } & \overbrace{\text { Cell extract }} & \text { Filtrate } & & \overbrace{\text { Cell extract }} & \text { Filtrate } \\ \text { K1-R } & 2.1 & 16.0 & & 4.6 & 1.6 \\ \text { B 13 } & 4.2 & 5.9 & 6.4 & 1.6 \\ \text { Ingbritt } & 0.5 & 6.1 & 3.5 & 1.5 \\ \text { OMZ176 } & 6.7 & 11.0 & 0.5 & 0.14\end{array}$

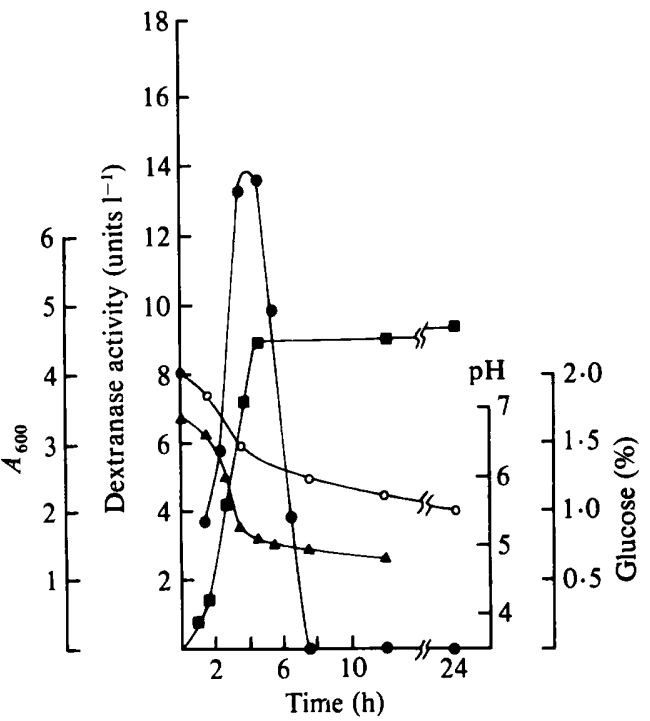

Fig. 1

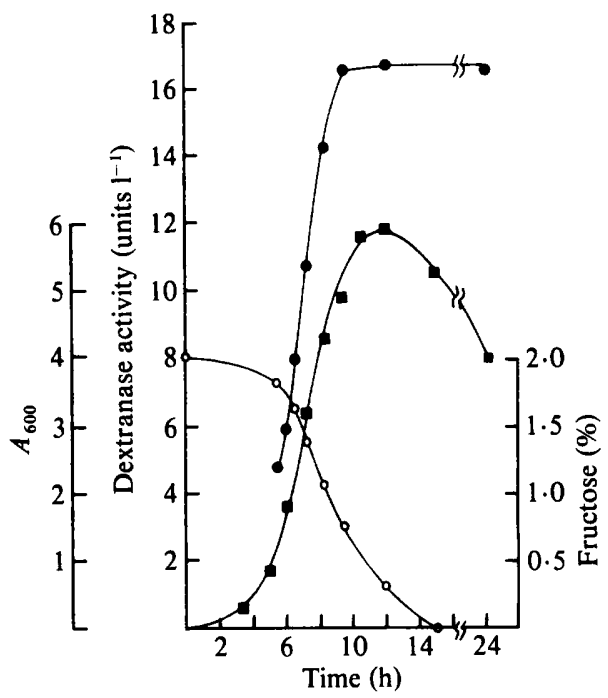

Fig. 2

Fig. 1. Release of endo-dextranase activity $(O)$ in batch culture of $S$. mutans strain OMZ176 in complete medium supplemented with $\mathrm{D}$-glucose $(2 \%, \mathrm{w} / \mathrm{v})$. The $\mathrm{pH}$ of the culture $(\Delta)$ was allowed to fall as a result of acid production by the bacteria. Samples were withdrawn at intervals for determination of culture density $\left(A_{600}\right)(\square)$, dry weight of the cells (not shown), and residual glucose $(\%, w / v)(O)$.

Fig. 2. Release of endo-dextranase activity (O) in batch culture of $S$. mutans strain Ingbritt in complete medium supplemented with $\mathrm{D}$-fructose $(2 \%, \mathrm{w} / \mathrm{v})$. The $\mathrm{pH}$ of the culture was controlled at $6 \cdot 0 \pm 0 \cdot 1$. Samples were withdrawn at intervals for determination of culture density $\left(A_{600}\right)(\square)$, dry weight of the cells, and residual fructose $(\%, w / v)(0)$.

\section{Effect of growth at controlled pH on endo-dextranase activity of cell-free filtrates}

Extracellular endo-dextranase activity of $S$. mutans strain OMZ176 was measured at intervals during growth in complete medium supplemented with $2 \%$ glucose, without $\mathrm{pH}$ control (Fig. 1). The dextranase activity increased during the early-exponential phase of growth but began to decline when the $\mathrm{pH}$ had fallen to 5 (about $4 \mathrm{~h}$ after inoculation). Thereafter the rate of glucose utilization was low, and the dextranase activity had fallen to zero after a further $4 \mathrm{~h}$. Qualitatively similar results (not shown) were obtained with strain Ingbritt grown under the same conditions; with this strain the $\mathrm{pH}$ had fallen to 5 by about $6 \mathrm{~h}$ after inoculation and dextranase was undetectable $10 \mathrm{~h}$ after inoculation. 
Table 2. Extracellular endo-dextranase activity of different Streptococcus mutans serotypes grown at pH 6 in medium supplemented with D-glucose or D-fructose (2\%)

\begin{tabular}{|c|c|c|c|c|c|c|c|}
\hline \multirow[b]{3}{*}{ Strain } & \multirow[b]{3}{*}{ Serotype } & \multicolumn{3}{|c|}{ Glucose medium } & \multicolumn{3}{|c|}{ Fructose medium } \\
\hline & & \multirow[b]{2}{*}{$\begin{array}{l}\text { Culture density } \\
\left(\mathrm{g} \text { dry wt } \mathrm{l}^{-1}\right)\end{array}$} & \multicolumn{2}{|c|}{ Dextranase activity* } & \multirow[b]{2}{*}{$\begin{array}{l}\text { Culture density } \\
\text { (g dry wt } \mathrm{l}^{-1} \text { ) }\end{array}$} & \multicolumn{2}{|c|}{ Dextranase activity* } \\
\hline & & & $\underset{1^{-1}}{\text { Units }}$ & $\begin{array}{c}\text { Units } \\
(\mathrm{g} \text { dry } w \mathrm{t})^{-1}\end{array}$ & & $\underset{1^{-1}}{\text { Units }}$ & $\begin{array}{c}\text { Units } \\
(\mathrm{g} \text { dry } w \mathrm{t})^{-1}\end{array}$ \\
\hline AHT & $a$ & 1.72 & 0 & 0 & 0.90 & 0 & 0 \\
\hline FA1 & $b$ & $2 \cdot 74$ & 0.15 & 0.06 & 2.65 & $1 \cdot 4$ & 0.53 \\
\hline BHT & $b$ & $2 \cdot 50$ & 0.23 & 0.09 & 2.63 & 0.72 & 0.27 \\
\hline $\mathrm{JC2}$ & $c$ & 1.41 & 0.57 & 0.40 & $1 \cdot 38$ & $1 \cdot 2$ & 0.87 \\
\hline GS5t & $c$ & $1 \cdot 38$ & 1.0 & 0.72 & $1 \cdot 36$ & $2 \cdot 4$ & 1.76 \\
\hline Ingbritt & $c$ & $1 \cdot 34$ & $10 \cdot 3$ & $7 \cdot 7$ & $1 \cdot 26$ & $23 \cdot 5$ & $18 \cdot 7$ \\
\hline B 13 & $d$ & $1 \cdot 42$ & 3.4 & 2.4 & $1 \cdot 35$ & $10 \cdot 6$ & 7.9 \\
\hline K 1-R & $d$ & $1 \cdot 55$ & $25 \cdot 0$ & 16 & - & - & - \\
\hline OMZ176 & $d$ & $2 \cdot 02$ & $22 \cdot 2$ & 11 & - & - & - \\
\hline LM $7 \dagger$ & $e$ & 0.45 & 0.4 & 1 & 0.82 & 0.4 & 0.5 \\
\hline OMZ175† & $f$ & 1.48 & 0.8 & 0.5 & $1 \cdot 23$ & 0 & 0 \\
\hline OMZ65† & $g$ & 1.44 & 0 & 0 & 1.33 & 0 & 0 \\
\hline
\end{tabular}

* One unit of activity is the amount of enzyme that releases $1 \mu \mathrm{mol}$ reducing power $\mathrm{min}^{-1}$.

$\dagger$ Results for these strains are from a single culture which was not repeated. In all other cases, similar results were obtained from up to 10 replicate cultures.

When $S$. mutans strain Ingbritt was grown in batch culture controlled at pH 6, in complete medium supplemented with $2 \%$ fructose (Fig. 2), dextranase was released during exponential growth, and once the maximum activity had been reached $\left[16.5\right.$ units $1^{-1} ; 10.2$ units (g dry wt cells) ${ }^{-1}$ ] there was no subsequent fall up to $24 \mathrm{~h}$ after inoculation. Similar results (not shown) were obtained in medium supplemented with $2 \%$ glucose [maximum activity 14.5 units $1^{-1} ; 8.2$ units ( $\mathrm{g}$ dry wt cells) ${ }^{-1}$ ]. These results may be compared with the maximum, but transitory, values of 6.5 units $1^{-1}$ and 6.0 units (g dry wt cells) $)^{-1}$ obtained with strain Ingbritt in glucose medium without $\mathrm{pH}$ control.

\section{Growth in medium supplemented with sucrose}

During growth in media containing sucrose, $S$. mutans extracellular D-glucosyltransferases synthesize $\alpha$-D-glucans which bind to dextran receptors on the cell surface (McCabe, 1976). Under this condition it was possible that dextranase might also become cell-associated because of its affinity for its own substrate. However, the distribution of dextranase activity of Ingbritt cells and culture filtrate was not altered when sucrose replaced glucose in the medium. Dextranase activity increased throughout the exponential phase of growth, finally reaching a value of 11.5 units $1^{-1}$. Thus, growth conditions under which D-glucosyltransferases became cell-associated did not influence the release of dextranase, and $95 \%$ of the total dextranase activity was found in the cell-free filtrate.

\section{Dextranase activity of $S$. mutans strains grown in medium supplemented with D-glucose or D-fructose}

Strains chosen from the seven identified serotypes of $S$. mutans were grown in dialysed medium with the $\mathrm{pH}$ controlled at 6.0 and harvested early in the stationary phase. Extracellular dextranase activity was generally about twofold higher in fructose medium than in glucose medium. Representative strains of serotype $d$ clearly displayed the highest dextranase activity, and only one strain (Ingbritt) from serotype $c$ showed comparable activity (Table 2). Serotype $b$ strains released less enzyme than those of serotype $c$, and the single representatives of serotypes $a, e, f$ and $g$ showed little or no activity under these conditions. 
Table 3. Effect of medium composition on the release of dextranase activity

\begin{tabular}{llll}
\multicolumn{1}{c}{ Strain } & Medium & $\begin{array}{c}\text { Glucose } \\
(\%)\end{array}$ & $\begin{array}{c}\text { Dextranase activity } \\
\text { [units }(\mathrm{g} \text { dry wt cells) }\end{array}{ }^{-1}$ ] \\
Ingbritt & Dialysed & 2 & $7 \cdot 7$ \\
Ingbritt & Complete & 2 & $8 \cdot 2,8 \cdot 5,6 \cdot 1$ \\
Ingbritt & Complete & $0 \cdot 5$ & $0 \cdot 70,0 \cdot 4,1 \cdot 6$ \\
K1-R & Complete & 2 & 16 \\
K1-R & Complete & $0 \cdot 5$ & $4 \cdot 9$ \\
OMZ176 & Complete & 2 & $15,11,8$ \\
OMZ176 & Complete & $0 \cdot 5$ & $2 \cdot 2,0$
\end{tabular}

\section{Effects of glucose concentration on dextranase release}

A reduction in glucose concentration from $2 \%$ to $0.5 \%$ resulted in a fall of up to $90 \%$ in dextranase activity per g dry wt of cells (Table 3). At the lower concentration of glucose there was more variability in the activity measured in different batches, and on one occasion, strain OMZ176, one of the best dextranase producers, was devoid of activity. Replacement of complete medium with dialysed medium did not affect the yield of dextranase.

\section{DISCUSSION}

A detailed examination of the specificity and action pattern of $S$. mutans endo-dextranase proved that the main hydrolysis products from dextran were isomaltotriose, isomaltotetraose and isomaltopentaose (Pulkownik \& Walker, 1977, Pulkownik et al., 1978). D-Glucose was not a product of endo-dextranase action. In contrast, glucose is the only product of dextran hydrolysis by the exo-dextranase which is formed by some strains of $S$. mutans. This specificity clearly distinguished between the two types of dextranase. The exo-enzyme was mainly intracellular, and its activity in the culture filtrate was so low that its activity could only be determined by measuring the rate of release of glucose from isomaltose: no release of glucose was detected when isomaltose was replaced by dextran which is a poorer substrate for the enzyme (Dewar \& Walker, 1975). Dextran was used as the substrate for the experiments described in this paper, so only the activity of the endo-enzyme has been studied. The endo-dextranase activity of intracellular extracts of several strains of $S$. mutans was reported earlier (Dewar \& Walker, 1975), and we have now presented values for the extracellular endo-dextranase of selected strains.

Strains from serotypes $c$ and $d$ were the most active producers of dextranase. The enzyme was released early in the exponential phase of growth, and dextranase production was clearly a property associated with rapidly growing cells. Any conditions that were not conducive to rapid growth, such as a low concentration of glucose or a $\mathrm{pH}$ below 5, gave a significantly lower enzyme activity (Table 3; Fig. 1). Unless the $\mathrm{pH}$ of the culture was controlled, extracellular enzyme produced early in the exponential phase became completely inactivated by the adverse conditions so that the activity could not be detected when the culture reached the stationary phase. Dextranase was absent in cultures of $S$. mutans growing slowly under glucose limitation at a mean generation time of $14 \mathrm{~h}$ (Walker et al., 1980). The relationship between growth rate and dextranase production should therefore be studied under defined conditions such as can be obtained in a chemostat, which is an ideal system for studying a growth rate-linked property. In the closed system of batch culture where the environmental conditions are essentially variable, it has not proved possible to obtain completely consistent results for dextranase activity between batches. Nevertheless, by controlling the $\mathrm{pH}$, by providing sufficient glucose and by harvesting near the end of the exponential phase, we have shown that activities up to 25 units ( 1 cell-free filtrate $)^{-1}$ can be obtained. It has long been known that addition of dextranase to incubation mixtures 
Table 4. Relationship between the dextranase activity of oral streptococci, the methylation analysis of their $\alpha-\mathrm{D}-$ glucans, and the hydrolysis of water-insoluble glucans by the endo-( $1 \rightarrow 6)-\alpha$-D-glucanase of Bacillus coagulans NRRL B-3949

The methylation analysis and the determination of the limit of hydrolysis by endo-dextranase were as described by Hare et al. (1978).

\begin{tabular}{|c|c|c|c|c|}
\hline \multirow[b]{3}{*}{ Source of glucan } & \multicolumn{3}{|c|}{ Linkage analysis } & \multirow[b]{3}{*}{$\begin{array}{c}\text { Hydrolysis } \\
(\%)\end{array}$} \\
\hline & \multicolumn{2}{|c|}{ Methyl ether (mol \%) } & \multirow[b]{2}{*}{$\begin{array}{c}\text { Linkage Ratio } \\
(1 \rightarrow 6) /(1 \rightarrow 3)\end{array}$} & \\
\hline & $\overparen{2.3 .4-T r i-O-M e-D-G l c}$ & $2.4,6-$ Tri-O-Me-D-Glc & & \\
\hline \multicolumn{5}{|l|}{$\begin{array}{l}\text { S. mutans serotype } d \\
\text { (high dextranase) }\end{array}$} \\
\hline$K] \cdot R$ & 11 & 64 & $0 \cdot 17$ & 5 \\
\hline OMZ176 & 18 & 57 & 0.31 & 22 \\
\hline $\mathrm{B} 13$ & 11 & 64 & 0.17 & 3 \\
\hline \multicolumn{5}{|l|}{$\begin{array}{l}\text { S. mutans serotype } c \\
\text { (moderate dextranase) }\end{array}$} \\
\hline Ingbritt & 36 & 53 & 0.67 & 31 \\
\hline NSWl & 32 & 51 & 0.63 & 38 \\
\hline NSW47 & 39 & 38 & 1.0 & 41 \\
\hline \multicolumn{5}{|l|}{$\begin{array}{l}\text { S. sanguis } \\
\text { (no dextranase) }\end{array}$} \\
\hline 804 & 49 & 15 & $2 \cdot 3$ & 62 \\
\hline ATCC 10558 & 47 & 17 & $2 \cdot 8$ & 53 \\
\hline NSW 13 & 48 & 19 & $2 \cdot 5$ & 39 \\
\hline
\end{tabular}

containing sucrose and D-glucosyltransferases will strongly inhibit the synthesis of D-glucans (Walker, 1972; Schachtele et al., 1975). The possibility that indigenous dextranases of $S$. mutans will similarly interfere with glucan synthesis by D-glucosyltransferases is nevertheless often neglected (Ebisu et al., 1974), and even when the presence of dextranase and its effect on glucose metabolism have been acknowledged, the actual amount of dextranase activity in the D-glucosyltransferase preparations is generally not quoted in defined units (Germaine et al. 1977). Schachtele et al. (1975) have shown that 5 units of dextranase $1^{-1}$ reduced the adherence of $S$. mutans cells to glass by $80 \%$, and as little dextranase as 2 units $\mathrm{l}^{-1}$ inhibited by $60 \%$ the synthesis of D-glucans from sucrose by crude $S$. mutans glucosyltransferase. Hence under optimum conditions, $S$. mutans cells release more than enough dextranase to inhibit the synthesis of $\alpha$-D-glucans by D-glucosyltransferases.

A comparison was made between the proportion of $(1 \rightarrow 6)$ - and $(1 \rightarrow 3)$-linked glucose sequences in glucans synthesized from sucrose by cell-free filtrates from various strains of Streptococcus spp., and the dextranase activity of each culture filtrate (Table 4). This provided circumstantial evidence for the ability of dextranase to modify the structure of the glucans. Strains from $S$. mutans serotype $d$, which were the best dextranase producers, gave the lowest values for the ratio of $(1 \rightarrow 6)$ - to $(1 \rightarrow 3)$-linked sequences, which ranged from $0 \cdot 17$ to 0.31 . Strains from serotype $c$, which released less dextranase, gave values in the range 1.0 to 1.6 . whereas $S$. sanguis strains, which produce little or no dextranase, gave the highest values (from 2.3 to 2.8 ). The glucans produced by serotype $d$ organisms were the most resistant to further hydrolysis by exogenous endo-dextranase (Table 4 ), in accord with the probability that the glucans were modified by indigenous dextranase so that most of the $(1 \rightarrow 6)$-linked sequences were already removed. In contrast, the glucans of $S$. mutans serotype $\mathcal{C}$ and $S$. sanguis were more susceptible to hydrolysis by added dextranase. The glucans of $S$. sanguis, which were synthesized in the absence of indigenous dextranase, contained the highest proportion of $(1 \rightarrow 6)$-linked glucose sequences, and were thus subject to extensive hydrolysis by exogenous dextranase (up to $62 \%$ ).

The cariogenic potential of oral streptococci is strongly correlated with the production of 
water-insoluble glucans that contain a high proportion of $(1 \rightarrow 3)$-linked sequences (Gibbons $\&$ Van Houte, 1975a), and this requires the participation of a specific D-glucosyltransferase designated GTF-I (Walker \& Hare, 1977). However, since $S$. mutans strains produce a second glucosyltransferase (GTF-S) that is responsible for the synthesis of $(1 \rightarrow 6)$-linked sequences (Fukui et al., 1974; Kuramitsu, 1975; Walker \& Hare, 1977), it is clear how the production of indigenous dextranase could also be a caries-conducive property. By decreasing the proportion of $(1 \rightarrow 6)$-linked sequences, the dextranase contributes towards the production of a predominantly $(1 \rightarrow 3)$-linked glucan. This would explain why dextranase-deficient mutant strains of $S$. mutans serotypes $c$ and $d$ produced virtually no smooth surface carious lesions in rats, compared with the severe effect of the wild-type strains (Tanzer et al., 1977).

Streptococcus sanguis produces copious amounts of a predominantly $(1 \rightarrow 6)$-linked glucan, and although it is far more abundant than $S$. mutans in dental plaque, it is apparently not capable of inducing caries in germ-free rats (Green et al., 1974). It is the proportion of $S$. mutans on human teeth that correlates to a high degree with caries activity (Gibbons \& Van Houte, $1975 b$ ). Although $S$. mutans serotype $c$ strains have received the most attention because of their prevalence, two recent studies have indicated the importance of serotype $d$ strains. Sidaway (1979), by accurate sampling of microscopically identified areas of tooth surface, found that serotype $d$ strains appeared more frequently than serotype $c$ in smooth-surface lesions of primary teeth. Huis in't Veld et al. (1979) in a study of the distribution of different serotypes in human dental plaque, found that serotype $d$ was predominantly present in approximal plaque of adults with active caries. These results support our conclusion that the caries-conducive properties of $S$. mutans serotype $d$ merit increased attention.

This investigation was supported by grants from the National Health and Medical Research Council of Australia, and the Australian Research Grants Committee.

\section{REFERENCES}

Dewar, M. D. \& Walker, G. J. (1975). Metabolism of the polysaccharides of human dental plaque. I. Dextranase activity of streptococci, and the extracellular polysaccharides synthesized from sucrose. Caries Research 9, 21-35.

Dygert, S., LI, L. H., Florida, D. \& Thoma, J. A. (1965). Determination of reducing sugar with improved precision. Analytical Biochemistry 13, 367-374.

Ebisu, S., Misaki, A., Kato, K. \& Kotani, S. (1974). The structure of water-insoluble glucans of cariogenic Streptococcus mutans, formed in the absence and presence of dextranase. Carbohydrate Research 38, 374-381.

Fukui, K., Fukui, Y. \& Moriyama, T. (1974). Some immunochemical properties of dextransucrase and invertase from Streptococcus mutans. Infection and Immunity 10, 985-990.

Germaine, G. R., Harlander, S. K., Leung, W. L. S. \& SCHACHTELE, C. F. (1977). Streptococcus mutans dextransucrase: functioning of primer dextran and endogenous dextranase in water-soluble and waterinsoluble glucan synthesis. Infection and Immunity 16, 637-648.

Gibbons, R. J. \& Fitzgerald, R. J. (1969). Dextraninduced agglutination of Streptococcus mutans, and its potential role in the formation of microbial dental plaques. Journal of Bacteriology 98, 34 1-346.
Gibbons, R. J. \& van Houte, J. (1973). On the formation of dental plaques. Journal of Periodontology 44, 347-360.

GibBons, R. J. \& VAN Houte, J. (1975a). Bacterial adherence in oral microbial ecology. Annual Review of Microbiology 29, 19-44.

Gibbons, R. J. \& van Houte, J. (1975b). Dental caries. Annual Review of Medicine 26, 121-136.

GreEN, R. M., DRUCKer, D. B. \& BlACKMORE, D. K. (1974). The reproducibility of experimental caries studies within and between two inbred strains of gnotobiotic rat. Archives of Oral Biology 19, 1049-1054.

Guggenheim, B. \& Burckhardt, J. J. (1974). Isolation and properties of a dextranase from Streptococcus mutans OMZ176. Helvetica odontologica acta 18, 101-113.

HARE, M. D. (1977). The enzymic synthesis and degradation of extracellular and intracellular polysaccharides by oral streptococci. M.Sc. thesis, University of Sydney, Australia.

Hare, M. D., Svensson, S. \& Walker, G. J. (1978). Characterization of the extracellular, water-insoluble $\alpha$-D-glucans of oral streptococci by methylation analysis, and by enzymic synthesis and degradation. Carbohydrate Research 66, 245-264.

van Houte, J. \& Saxton, C. A. (1971). Cell wall thickening and intracellular polysaccharide in micro- 
organisms of the dental plaque. Caries Research 5. $30-43$.

Huis IN'T VEld, J. H. J., VAN Palenstein Helderman, W. H. \& Backer Dirks, O. (1979). Streptococcus mutans and dental caries in humans: a bacteriological and immunological study. Antonie ian Leeuwenhoek 45. 25-33.

KlRamitsu. H. K. (1975). Characterization of extracellular glucosyltransferase activity of Streptococcus mutans. Infection and Immunity 12.738749.

MCCABE, M. M. (1976). Comments on adherence of Streptococcus mutans. Journal of Dental Research 55. C226-C228.

MCCAвE, M. M. \& Sмith. E. E. (1973). Origin of the cell-associated dextransucrase of Streptococcus mutans. Infection and Immunity 7, 829-838.

Pi.lownik, A. \& Walker, G. J. (1977). Purification and substrate specificity of an endo-dextranase of Streptococcus mutans K1-R. Carbohvdrate Research 54, 237-251.

Pilkownik. A., Thoma. J. A. \& Walker. G. J. $(1978)$. The action pattern and subsite map of Streptococcus mutans K1-R dextranase. Carbohidrate Research 61. 493-497.

Schachtele. C. G., Staat. R. H. \& Harlander. S. K. (1975). Dextranases from oral bacteria: inhibition of water-insoluble glucan production and adherence to smooth surfaces by Streptococcus mutans. Infection and Immunity 12.309-317.

SIDAW AY. D. A. (1979). Investigation of plaque flora of human carious teeth using a microsampling technique. Archices of Oral Biology 24. 257-263.

Spinel.t. D. M. \& Gibbons. R. J. (1974). Influence of culture medium on the glucosyl transferase- and dextran-binding capacity of Streptococcus mutans 6715 cells. Infection and Immunity 10. 1448-1451.
StaAt. R. H.. Gawronski, T. H. \& Schachtele, C. F. (1973). Detection and preliminary studies on dextranase-producing microorganisms from human dental plaque. Infection and Immunity 8, 10091016.

Tanzer, J. M., Freedman, M. L., Rinehimer, L. A., EIFERT, R., GRIFFITH, S. \& WOODIEL, F. (1977). Loss of virulence of glucanohydrolase-defective mutants of $S$. mutans. Journal of Dental Research 56. A 132.

WALKER. G. J. (1972). Some properties of a dextran glucosidase isolated from oral streptococci and its use in studies on dextran synthesis. Journal of Dental Research 51, 409-414.

W Alker, G. J. \& BuIlder, J. E. (1967). Metabolism of the reserve polysaccharide of Streptococcus mitis. Properties of $\alpha-(1 \rightarrow 6)$-glucosidase, its separation from transglucosylase, and the action of the two enzymes on branched oligosaccharides. Biochemical Journal 105, 937-942.

W ALKER, G. J. \& HARE, M. D. (1977). Metabolism of the polysaccharides of human dental plaque. II. Purification and properties of Cladosporium resinae $(1 \rightarrow 3)$ - $\alpha$-D-glucanase, and the enzymic hydrolysis of glucans synthesized by extracellular D-glucosyltransferases of oral streptococci. Carbohydrate Research 58. 415-432.

Walker, G. J. \& Pulkownik, A. (1973). Degradation of dextrans by an $\alpha-1,6$-glucan glucohydrolase from Streptococcus mitis. Carbohydrate Research 29. $1-14$.

W alker, G. J. \& Pulkownik, A. (1974). Action of a-1,6-glucan glucohydrolase on oligosaccharides derived from dextran. Carbohydrate Research 36, 53-66.

Walker, G. J., Murray, V. L. \& Morrey-Jones. J. G. (1980). Regulation of dextranase synthesis by Streptococcus mutans. FEBS Letters 115, 206-208. 